\title{
MICROBIAL ACTIVITY REGULATION OF VOLATILE ORGANIC COMPOUNDS WITH POTENTIAL FUEL OXYGENATE WITHIN EAST TAIJINAR SALT LAKE, CHINA
}

\author{
LU, X. H. ${ }^{1,2,3}-$ ZHANG, Y. S. ${ }^{4}-$ YI, L. ${ }^{1,2}-$ SU, W. G. ${ }^{1,2}-$ MA, Z. ${ }^{1,2,3}-$ HAN, F. Q. ${ }^{1,2^{*}}$ \\ ${ }^{1}$ Key Laboratory of Comprehensive and Highly Efficient Utilization of Salt Lake Resources, \\ Qinghai Institute of Salt Lakes, Chinese Academy of Sciences, Xining, Qinghai 810008, China \\ ${ }^{2}$ Qinghai Provincial Key Laboratory of Geology and Environment of Salt Lakes, Xining, \\ Qinghai 810008, China \\ ${ }^{3}$ University of Chinese Academy of Sciences, Beijing 100049, China \\ ${ }^{4}$ The Third Geological Exploration Institute of Qinghai Province, Xining, Qinghai 810000, \\ China \\ ${ }^{*}$ Corresponding author \\ e-mail: hanfq@isl.ac.cn \\ (Received $13^{\text {th }}$ Aug 2021; accepted $28^{\text {th }}$ Oct 2021)
}

\begin{abstract}
There is still limited information on the microbial communities and volatile organic compounds of different sediment types within salt lakes such as the East Taijinar Salt Lake, China. This study determined the variability in the ecogenomics and volatile organic compounds (VOCs) with fuel oxygenate potential of the different sediment types of the lake; clay sediment (NT), sandstone sediment (FS) and salt bearing sediment (SY) were examined to provide insight on the nature of bacterial communities and related VOCs in different forms of sediment. The results indicated distinct variability in microbial communities' diversity and metabolic functions between the different sediment types of the East Taijinar Salt Lake. Operational taxonomic Units (OTUs) were found to overlap more between the TN and FS types, and NT sediment type had the highest number of unique OTUs while SY had the least. The current study also reported the most highly abundant phylum group to be the proteobacteria, followed by firmicutes and then actinobacteria. Niveispirillum was shown to be the most abundant genus group and was recorded to have the highest abundance within the SY sediment type and the lowest within the NT sediment type. According to the results of the ACE, CHAO1, Shannon and Simpson indices, it was shown that higher diversity values occurred within the NT type and the lowest values were recorded within the SY sediment. Membrane transport, amino acid metabolism and carbohydrate metabolism were the major molecular activities across the sediment types causing ethanol to be the most abundant, while n-Hexyl acetate was the least abundant VOC across all the sediment types.
\end{abstract}

Keywords: microbial community diversity, molecular activities, salt lake eco-genomics, salt lake environment, sediment type

\section{Introduction}

Salt lakes, as their name indicates, are aquatic systems having significantly extreme environmental conditions, including higher salinity and other mineral content. Indeed, some of these salty aquatic ecosystems have been noted to have a moderately higher concentration of salt than sea water (Baxter, 2018). At the point when water vanishes from these lakes through evaporation or seepage, the accumulation of salt occurs, making salt lakes an incredible spot for deposition of salt particles. Moreover, as the point where the evaporation of water becomes higher than the amount flowing in, the accumulation of the deposited salts will steadily persist resulting in unique and extraordinary 
environmental conditions. Therefore, the extreme and unique climatic characteristics that dominate the salt lakes shape the life forms to develop adaptation strategies that enable them to withstand the existing physico-chemical parameters such as $\mathrm{pH}$, temperature, salinity etc. (Tazi et al., 2014). In most of the times the surrounding climatic and physicochemical parameters may result in the creation of acidic conditions with $\mathrm{pH}$ of $<5$, alkalinity condition with $\mathrm{pH}$ of $>9$, hyper condition with saltiness of $>35 \%$, low pressure condition of $>0.1 \mathrm{MPa}$, high temperature condition of $>40^{\circ} \mathrm{C}$, low temperature condition of $<5{ }^{\circ} \mathrm{C}$, and water pressure of $<0.80$ (Baxter, 2018). These conditions enable the survival of biotic communities that are extremophiles in nature, and they continue to develop and get duplicated with time (Han et al., 2017). In China, the salt lakes are described by their outstandingly rich properties such as higher temperatures, stronger radiation, high values of phosphates and carbonate deposits (Williams, 1991; Mianping et al., 1993; Zheng, 2011). Most salt lakes also have extreme conditions of environments that form in closed drainage basins exposed to high rate of evaporation processes. Due to their unique environment, most salty lakes develop high levels of carbonate and chloride salts, with pH range being predominant between 8 to > 12 (Jones et al., 1998; Kambura et al., 2016).

A reasonable difference exists in the organization of prokaryotic groups within the hypersaline lakes with $\mathrm{NaCl}$ levels of $>15 \%$ w/v and highly diluted waters with $\mathrm{NaCl}$ measures of about $5 \% \mathrm{w} / \mathrm{v}$. Under this condition photosynthetic process stands to be the main mechanism that takes up the formed nutrient compounds, with all the vigorous microbial networks that are mostly anaerobic in nature being the major trophic gatherings liable for cycling of carbon and sulfur (Lin et al., 2017). Precise scientific studies have demonstrated that the microorganisms are alkaliphilic and several of them fall under closely related taxa, while a few others portray no solid linkages to major known groups of prokaryotes. These alkaliphiles are boundless and in this manner appears to be extraordinary to the hypersaline lakes, and continue to occur independently within the created climatic condition (Yu and Kuenen, 2005). Despite the current salty lakes being geographically young, they have most likely existed since archaean occasions, allowing them to advance into free networks of alkaliphiles (Jones et al., 1994; Yu and Kuenen, 2005; Grant and Sorokin, 2011).

Investigations of hypersaline biological systems regularly yield novel organic entities and add to better comprehension of extreme conditions (Hollister et al., 2010). Halophiles are moderately unexplored as possible sources of novel species. Furthermore, little is thought about the culturable bacterial variety with flourishing capacity in hypersaline lakes (Guan et al., 2020). Present day studies on the microbiology of Great Salt Lake have contributed to molecular methodologies and provided proper understanding of the surrounding environment. The investigation of Great Salt Lake by researchers depicting these small occupants of the saline solution enlighten the bigger terminal lake with its numerous aspects, human driven impacts, and consistently changing shorelines (Baxter, 2018). Halophilic and halotolerant forms of microorganisms stand out as dependable sources of salt-lenient enzymatic resources with potential use in different bio-based technological measures where high salinity ranges would somehow hinder enzymatic changes. Indeed, some salty lakes have been found to harbor different promising types of microorganisms that can readily create mechanically important enzymatic materials (Ruginescu et al., 2020). Indeed, the limiting osmotic conditions occurring in hypersaline conditions bring about diminishing metabolic variety with expanding saltiness and different microbial digestion systems have been depicted to occur even at high salt conditions (Oren et al., 1994). This creates the need to have proper geochemical 
understanding and to know the existing control mechanisms on microbial biology in saline-based lake conditions (Dong et al., 2006).

Biological systems experience exchange in significant atmospheric trace gases, incorporating volatile organic compounds (VOCs), which are a little but exceptionally receptive piece of the carbon cycle. Majority of the formed VOCs are produced by microorganisms, making it necessary to undertake in-depth studies to provide detailed information on the relationships between microorganisms and the major compounds (Insam and Seewald, 2010). VOCs have natural beneficial properties that contributes to the function and stability of the environment (Mellouki et al., 2015; Wu et al., 2020). VOCs are useful portion of the ecosystem that ensure the availability of supplements for the development of most cellular micro-organisms and intervene in coordination and interactions within the cells. Nonetheless, barely any investigations have zeroed in on the impacts of VOCs on prokaryotic varieties and surrounding environment. There is limited information on the influence of VOCs on the variety, creations, and organization of prokaryotic networks in saline silt (Ding et al., 2020). Indeed, it has been shown that water and sediments of different lakes can harbor unique and novel prokaryotic diversity (Mesbah et al., 2007).

Salt Lake environments such as the East Taijinar Salt Lake, China are important parts of the ecosystems (Last, 2002). Notwithstanding their raised salinities, saline lakes undertake numerous functions that form the foundation of economically productive source of mineral and other ecosystem functions (Chindapana et al., 2018). It is the interaction between the biological, chemical, and physical parameters that dictates the nature and amount of salt ions and minerals within the salt lake environment (Britannica, 2019). Despite this, more studies have only focused on the location, morphology and chemical characteristics, with much focus on the types of salts but less attention on the biological components such as microbial communities under related VOC characteristics (Boggsa et al., 2006; Freire et al., 2014). Therefore, this study was purposed to undertake ecogenomics and volatile organic compounds studies on different sediment types of East Taijinar Salt Lake to provide holistic insight on the nature of bacterial communities and related VOC at different sediment types for future management exploitation of the resources within the salt like regimen.

\section{Materials and methods}

\section{Study area}

The study was undertaken at the East Taijinar Salt Lake located at $37^{\circ} 21^{\prime} 54^{\prime \prime}-$ $37^{\circ} 36^{\prime} 05^{\prime \prime} \mathrm{N}$ and $93^{\circ} 45^{\prime} 33^{\prime \prime}-94^{\circ} 06^{\prime} 48^{\prime \prime} \mathrm{W}$ (Figure 1). It is positioned in the middle of the Qaidam Basin, distributed in the direction of NW-SE, with an area of $121.5 \mathrm{~km}^{2}$ and a depth of $0.6 \mathrm{~m}$. It is an inland Salt Lake, which is mainly supplied by the East Taijinar River from the Kunlun Mountains in the southwest and excreted by evaporation. The brine is a magnesium sulfate subtype with a $\mathrm{pH}$ of 7.9, and is rich in lithium, boron, potassium, and magnesium. Due to the paleoclimate, neotectonic movement and provenance replenishment, the formation conditions of the lake sediments are relatively complex. There are two halite deposits in different periods, the upper layer is the Holocene sedimentary and the lower is Pleistocene sedimentary. 


\section{Sampling site and procedure}

The sediment samples used in this study were obtained from a depth profile within the middle of the dry salt flats at a location of $93^{\circ} 57^{\prime} 04^{\prime \prime} \mathrm{N}$ and $37^{\circ} 27^{\prime} 46 \mathrm{~W}$ using a polyvinyl chloride corer. A total of nine samples per site were taken from three different lithologic strata; clay (NT1-NT3), sandstone (FS1-FS3), and salt-bearing (SY1-SY3). The samples were kept in ice and transported to the Key Laboratory of Comprehensive and Highly Efficient Utilization of Salt Lake Resources, Qinghai Institute of Salt Lakes, Chinese Academy of Sciences for further processing and analysis.

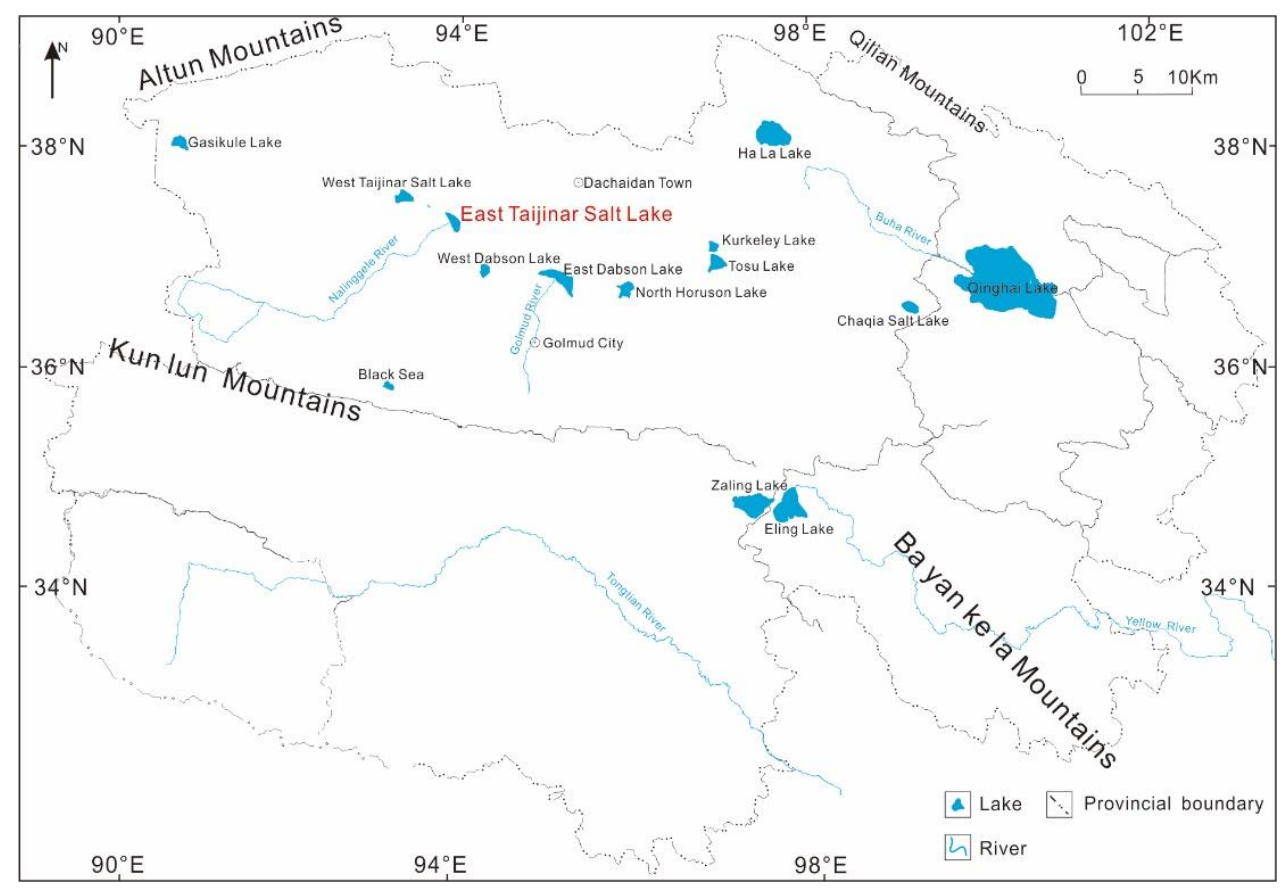

Figure 1. Map of the study area showing East Taijinar Salt Lake

\section{DNA isolation and metagenomic sequencing}

The extraction of the total genomic DNA from the sediment samples was carried out with CTAB/SDS method. The DNA purity and concentration monitoring were accomplished on $1 \%$ agarose gels. Based on the concentration, the dilution of DNA was made to $1 \mathrm{ng} / \mu \mathrm{l}$ using sterile water. For the generation of amplicon, primer $16 \mathrm{~S} \mathrm{V3-V4:}$ 341F-806R, 18S V9: 1380F-1510R, ITS1: ITS1F- ITS2R were used. 16S /18S rRNA genes were subjected to amplification by applying the specific barcoded primers. The entire PCR reactions were accomplished in $30 \mu \mathrm{L}$ reactions having Phusion ${ }^{\circledR}$ High-Fidelity of $15 \mu \mathrm{L}$, Master Mix for PCR (New England Biolabs); of $0.2 \mu \mathrm{M}$ for both the forward and reverse primers, and estimated $10 \mathrm{ng}$ template DNA. The thermal cycling consisted of the initial denaturation which occurred within a temperature of 98 ${ }^{\circ} \mathrm{C}$ for a time period of 1 minute, followed by 30 cycles of denaturation within $98{ }^{\circ} \mathrm{C}$ for 10 seconds, then annealing within $50{ }^{\circ} \mathrm{C}$ for 30 seconds, and elongation at $72{ }^{\circ} \mathrm{C}$ for 60 seconds and final step was carried out at $72{ }^{\circ} \mathrm{C}$ for 5 minutes.

Quantification and qualification of the products of Polymerase chain reaction (PCR) involved same volume of $1 \mathrm{X}$ loading buffer (contained SYB green) that was added to the product of PCR and then electrophoresis was carried out on $2 \%$ agarose gel for the 
purpose of identification. Samples that possessed main strip which were bright and of between 400-450 bp were selected for further experimental analysis. For PCR products addition and purification, the PCR products were added together in equal density ratios. After that, the purification of the PCR products was undertaken by using AxyPrepDNA Gel Extraction Kit (AXYGEN). Preparation of library and sequencing was then achieved by generating sequencing libraries using NEB Next ${ }^{\circledR} U$ ltra $^{\mathrm{TM}}$ DNA Library Prep Kit (NEB, USA) taking note of the manufacturer's directives, with addition of index codes. The assessment of the quality of the library was accomplished on the Qubit@ 2.0 Fluorometer (Thermo Scientific) and Agilent Bioanalyzer 2100 system. Sequencing process was undertaken on an Illumina Miseq/HiSeq2500 platform where $250 \mathrm{bp} / 300 \mathrm{bp}$ paired-end reads were produced.

\section{Analysis of metagenomic data}

For matched paired end reads congregations, the combined paired-end reads from the first Deoxyribonucleic Acid (DNA) pieces were consolidated utilizing FLASH to blend combined end-reads when probably a portion of the reads covered the read created from the opposite edge of a similar DNA section. Matched end reads were relegated to each example as per the special barcodes. For Operational Taxonomic Unit (OUT) grouping and species comment, successions of investigation was undertaken using the UPARSE programming bundle utilizing the UPARSE-OTU and UPARSE-OTUref calculations. For investigation of alpha (inside examples) and beta (among tests) variety within-house Perl scripts were applied. Arrangements with $\geq 97 \%$ similitude were assigned to similar OTUs. The agent successions for each OTU were then picked and utilized in the RDP classifier to clarify ordered data for every delegate grouping. To process Alpha Diversity, the table of the OTU was checked and determined with three measurements: ACE, CHAO1, Shannon and Simpson were used to appraise the abundance of species; number of Species observed was used to assess the measure of novel OTU that exists in each category (Barker et al., 2010; Chao and Chiu, 2016; Thukral, 2017).

For Phylogenetic distance and community dissemination investigation, graphical portrayal of the overall variety of bacterial abundance at phylum unit to species unit was pictured utilizing Krona outline. Group investigation was done before principal component analysis (PCA), which was incorporated to decrease the element of the first factors utilizing the QIIME programming bundle which computes both the weighted and unweighted unifrac distance as phylogenetic proportions of beta variety. Unweighted unifrac distance was utilized in the process of Principal Coordinate Analysis (PCoA) method as well as the Unweighted Pair Group Method with Arithmetic mean (UPGMA) Clustering. PCoA assisted with getting main arranges and envision them from unpredictable, multidimensional information. Then again, UPGMA Clustering was utilized to describe the distance grid.

\section{Speciation and quantification of volatile organic compounds using GC-IMS}

Ionization of the VOC values were determined using the headspace-gas chromatography-ion mobility spectrometry (HS-GC-IMS) instrument (FlavorSpec ${ }^{\circledR}$ H1-00053, Gesellschaft für Analytische Sensorsysteme mbH (G.A.S.), Dortmund, Germany). This analytical work was undertaken within the G.A.S. Department of the Shandong HaiNeng Science Instrument Co., Ltd. (Shandong, China). The chromatographs separation was undertaken with an FS-SE-54-CB-1 capillary column (15 m, ID: $0.53 \mathrm{~mm}$ ), a radioactive ionization source (tritium; $6.5 \mathrm{KeV}$ ), and a 
heated spitless injector for auto-direct acquisition of the headspace volatile compounds samples from the samples and moved into the inside of the GC-IMS instrument. Before the GC-IMS analysis, the sample ( $1 \mathrm{~g})$ was subjected to heating at temperature of eighty degrees Celsius for twenty minutes in a box for incubation to form volatile elements. The injection volume was set at five hundred $\mu \mathrm{L}$, the injection speed setting was $0.6 \mathrm{~mL} \mathrm{~s}^{-1}$, and the injection temperature was set at $80{ }^{\circ} \mathrm{C}$. The temperature for the automatic headspace sampler was adjusted to $85^{\circ} \mathrm{C}$ within the time duration of 15 minutes. After injection of the sample, the VOCs were introduced into the multi-capillary column through the carrier gas for timely separation. Chromatographic separation was performed at $60{ }^{\circ} \mathrm{C}$ : the initial placement of the rate of the carrier gas flow was put at $2 \mathrm{~mL} \mathrm{~min}^{-1}$ for 2 minutes; the flow was then raised in linear trend till it achieved $15 \mathrm{~mL} \mathrm{~min}^{-1}$ over a time period of 8 minutes; it was raised up to a volume of $80 \mathrm{~mL} \mathrm{~min}^{-1}$ for a time duration of 10 minutes; and for the end, the flow acquired $150 \mathrm{~mL} \mathrm{~min}^{-1}$ within a time period of 5 minutes. The total run time took a time duration of $40 \mathrm{~min}$ so that it could achieve a better separation output. In consequence to the division within the capillary column at $60{ }^{\circ} \mathrm{C}$, the headspace was pushed into the ionization section for prior ionization, then forcefully pushed into the drift region by a shutter grid, and lastly moved into the IMS detector. The condition for working of the IMS were: $5 \mathrm{~cm}$ length of the drift tube and functioned at the same voltage of $400 \mathrm{~V} \mathrm{~cm}^{-1} ; 45{ }^{\circ} \mathrm{C}$ drift tube temperature with nitrogen of $99.999 \%$ purity and $150 \mathrm{~mL} \mathrm{~min}^{-1}$ for the rate of flow. Every sample was introduced to two tier analysis procedure using GC-IMS. The experimental results were given as the average value to reduce errors.

\section{Statistical analysis}

To affirm contrasts in the quantity of individual scientific groups, STAMP programming was used. LEfSe was utilized for the quantitative based examination of biomarkers inside the various groups to dissect information wherein the quantity of species was a lot higher than the quantity of tests and to give biological group clarifications to set up measurable importance, organic consistency, and impact size assessment of anticipated biomarkers. To distinguish contrasts of microbial networks within the two categories, ANOSIM and ADONIS were undertaken dependent on the Bray-Curtis uniqueness distance grids. The means for VOC information were compared through SPSS version 12, with 95\% as level of significance and P value of 0.05 .

\section{Results}

\section{Operational taxonomic unit analysis and distribution}

Analysis of common and unique bacterial Operational Taxonomic Units (OUTs) between different sediment types are provided in Fig. 2. The results indicated that more numbers of OTUs overlapped between the clay sediment (TN) and sandstone sediment (FS) types. The NT also had the highest number of unique OTUs while salt bearing sediment (SY) had the least.

\section{UPGMA cluster tree}

The result on the similarity between different samples is provided in Fig. 3. From this result, the highly abundant phylum group was the proteobacteria, followed by firmicutes and then actinobacteria. 

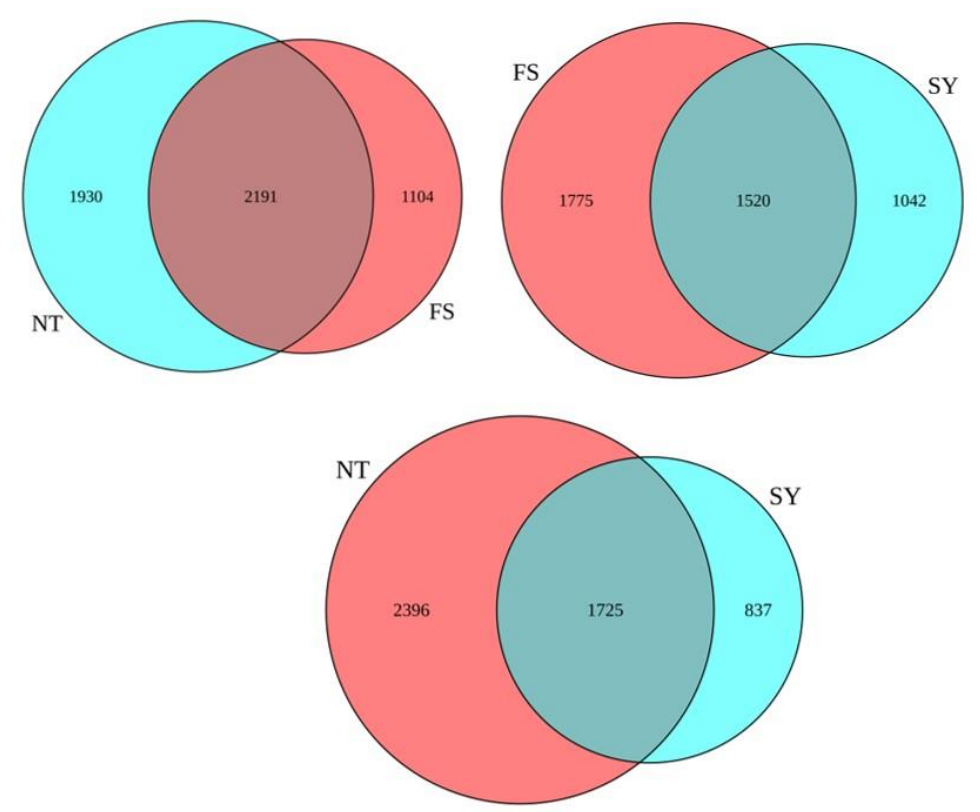

Figure 2. OTU relationship between the sediment types (NT is clay sediment, FS is sandstone sediment and SY is salt bearing sediment) through Venn

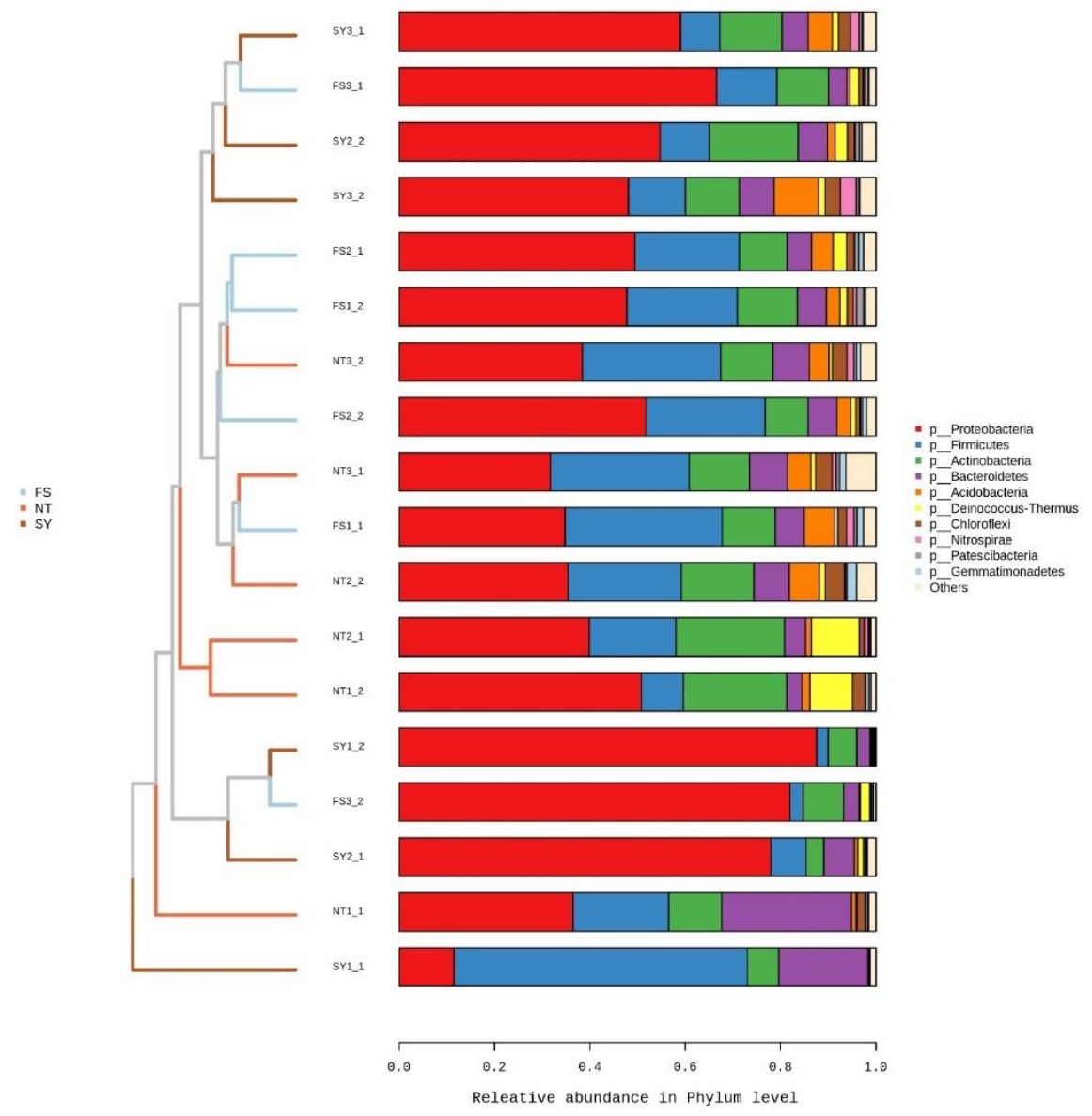

Figure 3. UpGMA cluster trees and community structure bar charts based on Unweighted Unifrac distance

APPLIED ECOLOGY AND ENVIRONMENTAL RESEARCH 20(1):447-464. http://www.aloki.hu • ISSN 15891623 (Print) • ISSN1785 0037 (Online) DOI: http://dx.doi.org/10.15666/aeer/2001_447464

(c) 2022, ALÖKI Kft., Budapest, Hungary 


\section{Analysis of species composition}

Based on the results of Fig. 4, the most dominant bacterial genus was Niveispirillum, its abundance was the highest within the salt bearing sediment (SY) and the lowest within the clay sediment (NT).

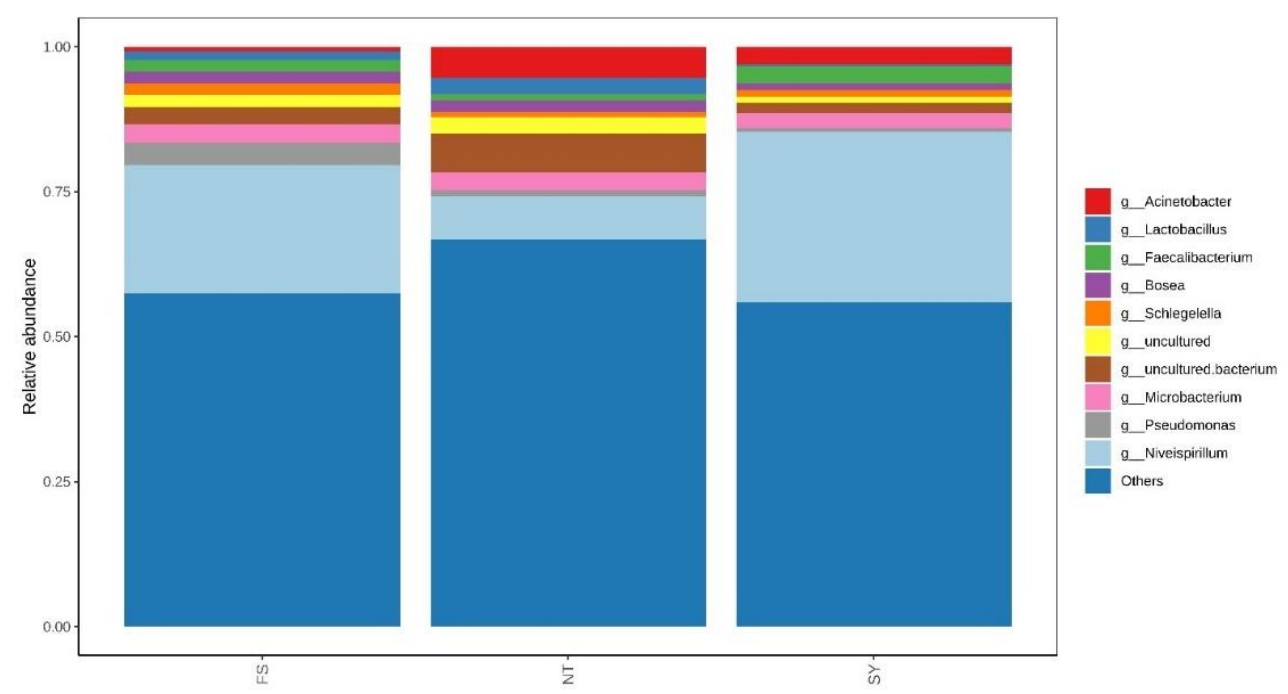

Figure 4. Graph of relative abundance of top ten genus at each sediment type

\section{Community heatmap graph}

Result on abundance of various genera based on heatmap analysis is provided in Fig. 5. The result indicated higher abundance of the dominant genera in NT sediment type and the lowest abundance in FS sediment type.

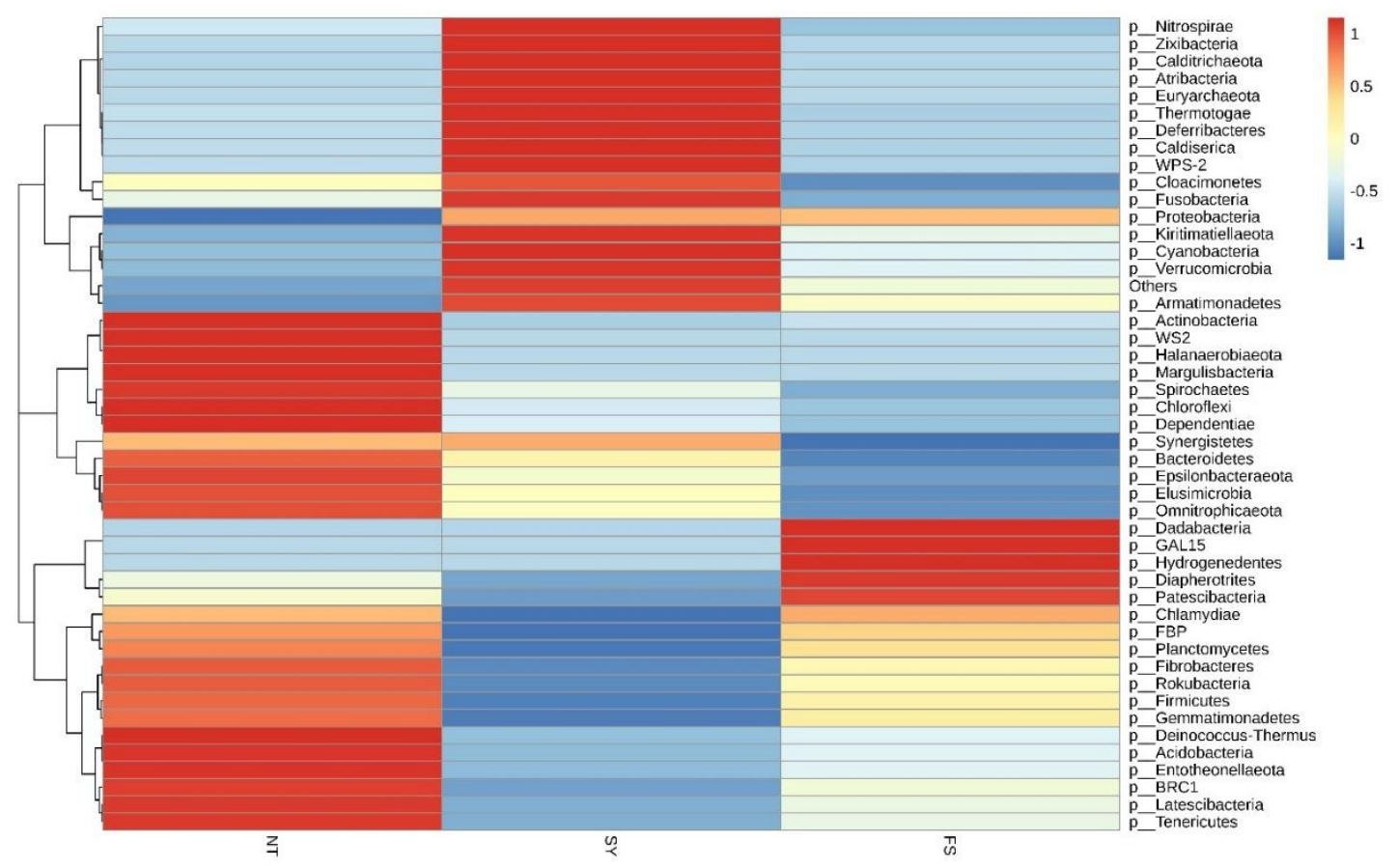

Figure 5. Cluster heat map of species abundance at each group gate level 


\section{Species diversity analysis}

Result on Alpha diversity index based on ACE, CHAO1, Shannon and Simpson are provided in Fig. 6. Based on this result, highest diversity occurred within the clay sediment (NT) and the lowest occurred within the salt bearing sediment (SY).
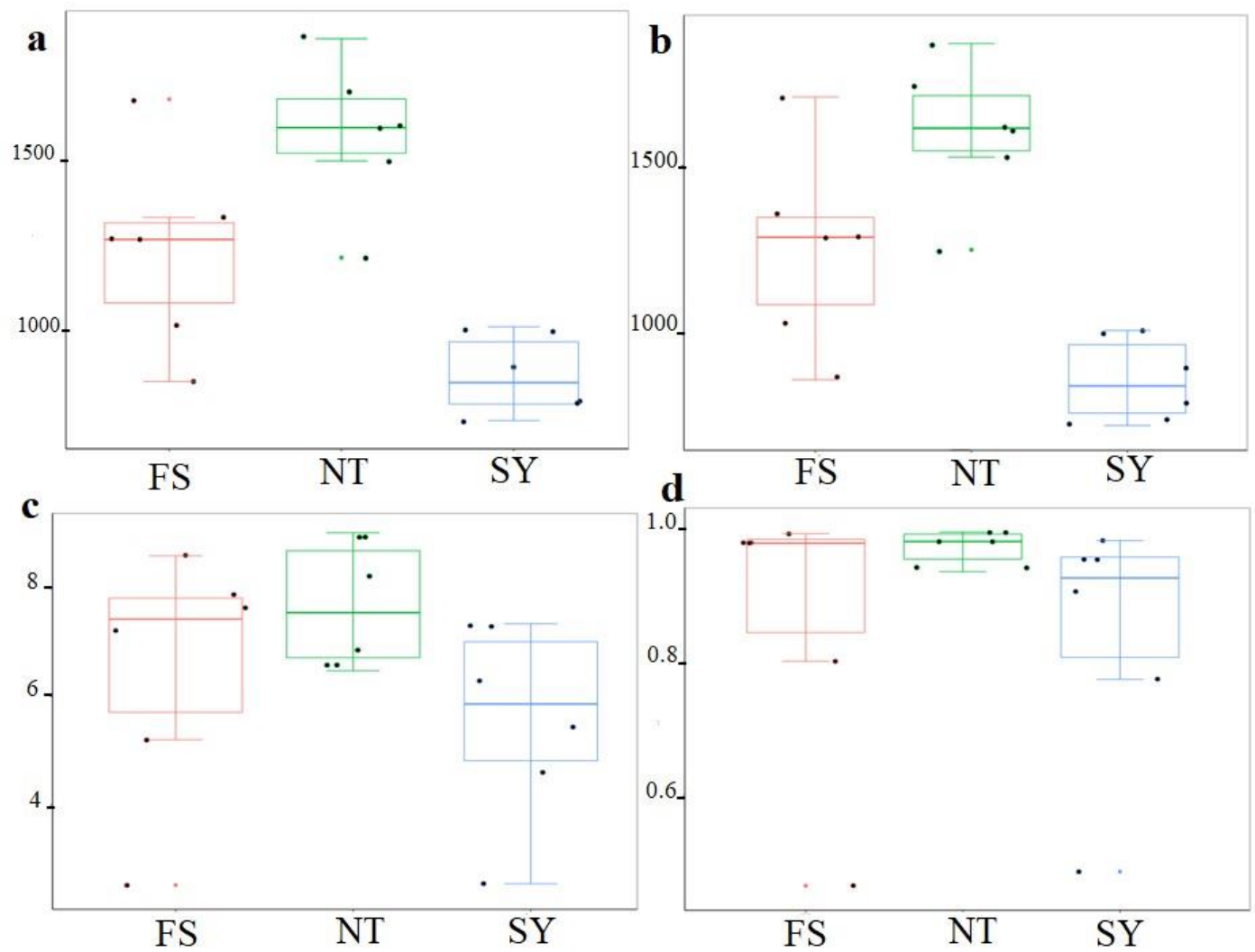

Figure 6. Box whisker plots for Alpha diversity index based on ACE (a), CHAOI (b), Shannon (c) and Simpson (d) indices across the different sediment types (FS is sand stone sediment, NT is clay sediment and SY is salt bearing sediment

\section{Functional feature prediction}

The Kyoto Encyclopedia of Genes and Genomes (KEGG) functional prediction analysis was used to study the metabolic function changes of community samples at different sediment types. The result on biological pathways through KEGG is provided in Fig. 7. The Clusters of Orthologous Groups (COGs) was used to complement KEGG to compare the protein sequences of complete genomes at different sediment types. The results on functional prediction through Clusters of Orthologous Groups (COGs) are provided in Fig. 8. LEfSe analysis based on taxonomical composition of samples according to different grouping conditions for linear discrimination analysis (LDA), was used to find out the classification of samples and feature entries with significant differences. Result on group means for the functional genes through the LDA scores is provided in Fig. 9. 


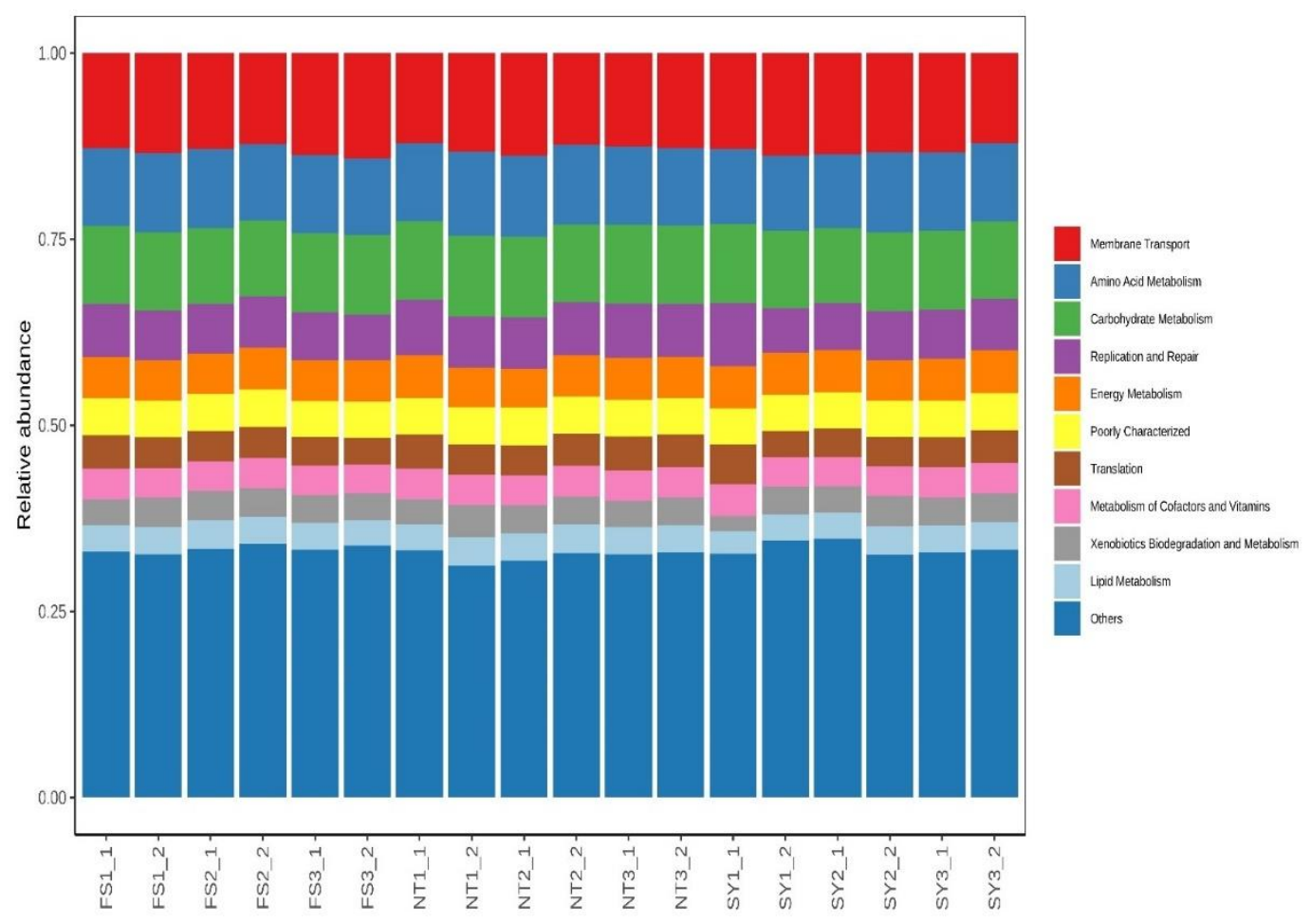

Figure 7. Bar graph of biological activities through KEGG (Kyoto Encyclopedia of Genes and Genomes)

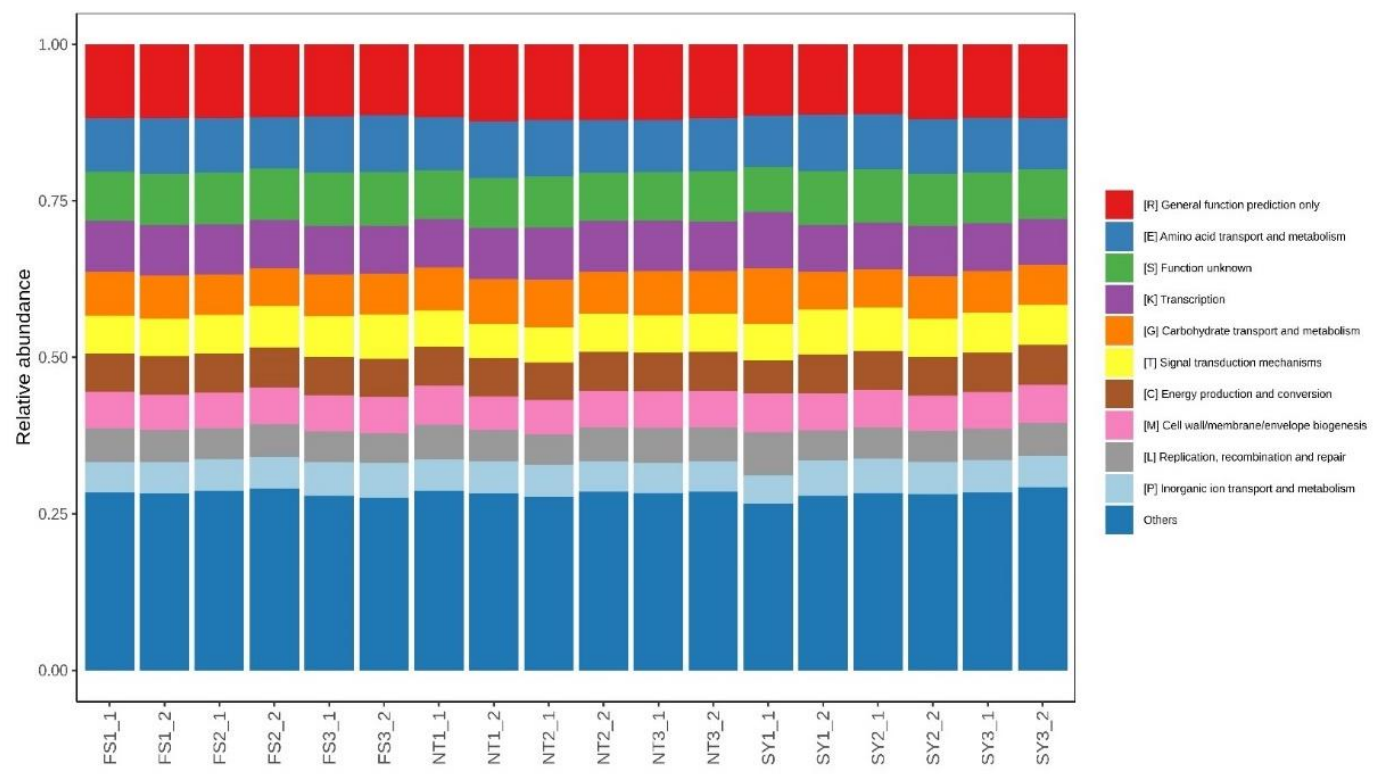

Figure 8. Bar graph for functional prediction through Clusters of Orthologous Groups (COGs)

\section{Volatile organic compound (VOC)}

Results on the values of volatile organic compound (VOC) across the different sediment types are provided in Table 1. From the results, it was shown that values for ethanol, 1-Butanol M, 2-Octanol and n-Hexyl acetate were relatively the highest within 
the clay sediment, the values for Cyclohexanone, 5-Methyl-3-heptanone, formic acid, ethyl propionate, propyl butanoate $\mathrm{M}$, hexanal $\mathrm{M}$ and Benzaldehyde were relatively the highest within the sand stone sediment while values for Acetone, ethyl acetate M, Butyl butyrate M, Furfural M, Heptanal, Octanal, Nonanal M and Nonanal D were the highest within the salt bearing sediment. Across all the sediment types, ethanol was the most abundant while n-Hexyl acetate was the least abundant VOC.

$\mathbf{a}$

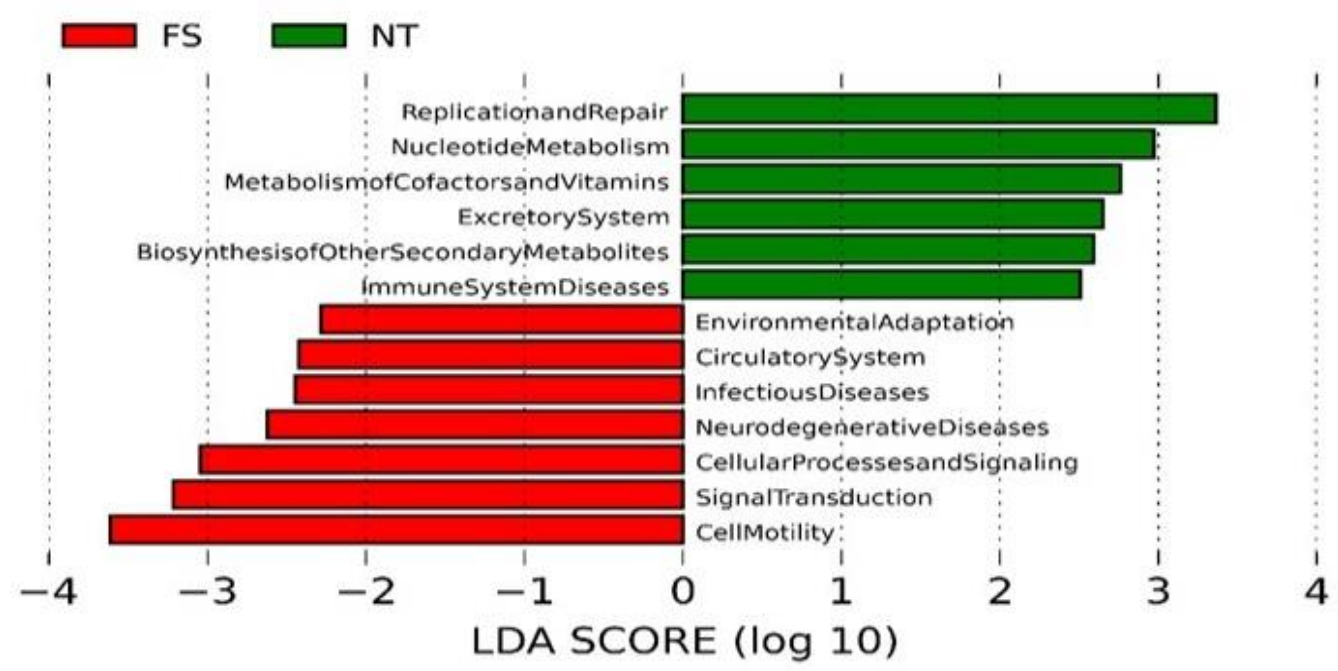

b
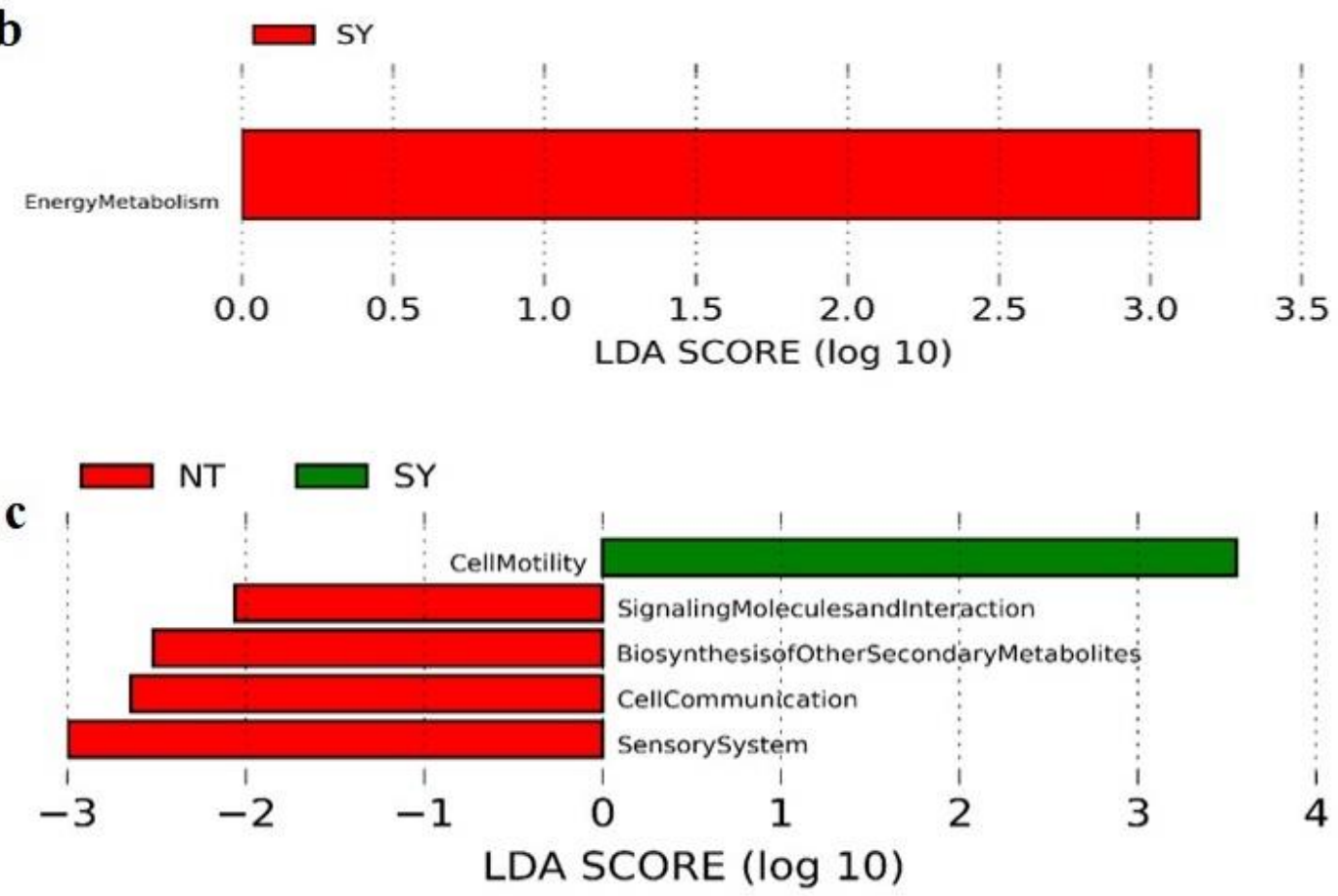

Figure 9. Graph of means for the functional genes through the LDA scores for different groups FS vs NT (a), SY vs $S F(b)$ and NT vs $S Y(c)$ 
Table 1. Spatial variation in the values of volatile organic compound (VOC) across the different sediment types (NT is clay sediment, FS is sandstone sediment and SY is salt bearing sediment, values followed by the different letter across the column are significantly different at $P=0.05$ )

\begin{tabular}{c|c|c|c|c}
\hline VOC & NT & FS & SY & P-value \\
\hline ethanol & $0.1584 \pm 0.11 \mathrm{a}$ & $0.1318 \pm 0.09 \mathrm{~b}$ & $0.0676 \pm 0.02 \mathrm{c}$ & 0.0442 \\
1-Butanol M & $0.0706 \pm 0.02 \mathrm{a}$ & $0.0361 \pm 0.03 \mathrm{~b}$ & $0.0674 \pm 0.01 \mathrm{a}$ & 0.0015 \\
2-Octanol & $0.0103 \pm 0.011 \mathrm{a}$ & $0.0078 \pm 0.01 \mathrm{~b}$ & $0.0024 \pm 0.00 \mathrm{~b}$ & 0.0224 \\
n-Hexyl acetate & $0.0103 \pm 0.01 \mathrm{a}$ & $0.0038 \pm 0.00 \mathrm{~b}$ & $0.0038 \pm 0.00 \mathrm{~b}$ & 0.0042 \\
Cyclohexanone & $0.0066 \pm 0.01 \mathrm{a}$ & $0.0320 \pm 0.03 \mathrm{~b}$ & $0.0022 \pm 0.00 \mathrm{c}$ & 0.0001 \\
5-Methyl-3-heptanone & $0.0142 \pm 0.02 \mathrm{a}$ & $0.0571 \pm 0.05 \mathrm{~b}$ & $0.0011 \pm 0.00 \mathrm{c}$ & 0.0028 \\
formic acid & $0.0202 \pm 0.01 \mathrm{a}$ & $0.0308 \pm 0.01 \mathrm{a}$ & $0.0161 \pm 0.00 \mathrm{a}$ & 0.0645 \\
ethyl propionate & $0.0250 \pm 0.03 \mathrm{a}$ & $0.0473 \pm 0.01 \mathrm{~b}$ & $0.0045 \pm 0.00 \mathrm{c}$ & 0.0037 \\
propyl butanoate M & $0.0445 \pm 0.00 \mathrm{a}$ & $0.1129 \pm 0.04 \mathrm{~b}$ & $0.0486 \pm 0.01 \mathrm{a}$ & 0.0019 \\
hexanal M & $0.0398 \pm 0.02 \mathrm{a}$ & $0.0665 \pm 0.03 \mathrm{~b}$ & $0.0453 \pm 0.01 \mathrm{a}$ & 0.0036 \\
Benzaldehyde & $0.0205 \pm 0.02 \mathrm{a}$ & $0.0498 \pm 0.04 \mathrm{~b}$ & $0.0153 \pm 0.01 \mathrm{a}$ & 0.0044 \\
Acetone & $0.0209 \pm 0.01 \mathrm{a}$ & $0.0184 \pm 0.01 \mathrm{a}$ & $0.0281 \pm 0.02 \mathrm{a}$ & 0.0721 \\
ethyl acetate M & $0.0137 \pm 0.01 \mathrm{a}$ & $0.0021 \pm 0.00 \mathrm{~b}$ & $0.0304 \pm 0.01 \mathrm{c}$ & 0.0046 \\
Butyl butyrate M & $0.0344 \pm 0.01 \mathrm{ab}$ & $0.0234 \pm 0.04 \mathrm{~b}$ & $0.0418 \pm 0.00 \mathrm{a}$ & 0.0013 \\
Furfural M & $0.0047 \pm 0.00 \mathrm{a}$ & $0.0057 \pm 0.01 \mathrm{a}$ & $0.0216 \pm 0.01 \mathrm{~b}$ & 0.0035 \\
Heptanal & $0.0106 \pm 0.01 \mathrm{a}$ & $0.0087 \pm 0.00 \mathrm{~b}$ & $0.0135 \pm 0.00 \mathrm{a}$ & 0.0042 \\
Octanal & $0.0091 \pm 0.01 \mathrm{a}$ & $0.0102 \pm 0.01 \mathrm{~b}$ & $0.0140 \pm 0.00 \mathrm{~b}$ & 0.0018 \\
Nonanal M & $0.0412 \pm 0.03 \mathrm{a}$ & $0.0934 \pm 0.06 \mathrm{~b}$ & $0.0283 \pm 0.01 \mathrm{c}$ & 0.0034 \\
Nonanal D & $0.0059 \pm 0.01 \mathrm{a}$ & $0.0016 \pm 0.00 \mathrm{a}$ & $0.0093 \pm 0.01 \mathrm{a}$ & 0.0001 \\
\hline
\end{tabular}

\section{Discussion}

\section{Bacterial community structure}

The study aimed at unlocking the characteristics of different sediment types within the East Taijinar Salt Lake based on the microbial community assemblage and types and concentrations of the volatile organic compounds. Halophiles are moderately neglected yet they are significant sources of novel species. Be that as it may, little is also understood about the culturable bacterial variety that flourish in hypersaline lakes despite groups such as Rhodothermaeota having been linked to these unique ecosystems (Ventosa et al., 2015; Guan et al., 2020). Moreover, the current acknowledged model of local area structure in hypersaline conditions is that the archaeal groups Haloquadratum waslbyi, the bacteroidete Salinibacter ruber and nanohaloarchaea are dominant members at higher levels of salinity, while more assorted archaeal and bacterial groups are seen in natural surroundings with moderate salt conditions. Metagenomic examination provides understanding into the detachment and portrayal of the major microorganisms in saline environment. For instance, a study had identified and described gammaproteobacterium Spiribacter salinus as a principal microbe of saline lake sediment. Based, on the current study, it was demonstrated through analysis of common and unique operational taxonomic units (OTUs) between different sediment types that more OTUs overlapped between the clay sediment (TN) and sandstone sediment (FS) types. Additionally, the NT also had the highest number of unique OTUs while salt bearing sediment (SY) had the least. This pointed out the influence of salt within the sediment on the survival of bacteria. 
Indeed, it highlighted that the salt bearing sediment as having unique environment to that of clay and sand sediment, hence had a more distinct OTUs from the other two forms of sediment types. This also agrees with a study by Kasper et al. (2007) which indicated that the growth performance of most bacteria isolates depends very much on the salinity levels of the ecosystem and only few and unique members can thrive in such ecosystems with extreme conditions.

Salty sediments have been shown to harbor a diverse bacterial community that differs spatially and temporary, and based on sediment characteristics (Rasuk et al., 2016). These conditions can turn out to be very hypersaline when dry, proposing that this variation in condition changes based on the occurrence of both flooding and high saltiness conditions (Vogt et al., 2017). It has also been shown that the salt tolerant microbial networks are overwhelmed by normal halotolerant to halophilic microorganisms, which may encounter shifts in community structure, richness, and variety along the ecological gradient. Through this shift, the exceptionally adjusted specialized groups may predominantly be found at the extremes, while less specialized groups with wide resilience reaches may dominate within the areas with moderate conditions. This demonstrated that the bacterial lavishness and variety may increment from the areas with higher salinities to areas with lower salinities (Rasuk et al., 2016). The current study also reported that most phylum group with high abundance were proteobacteria, followed by firmicutes and then actinobacteria, which were both more dominant across all the sediment types. The outcome of this study gives an exhaustive perspective on microbial survival specialization based on salt content within the lake sediments as had also been confirmed by Beazley et al. (2012).

A study on the most geochemically extreme salty lakes on Earth such as Lake Magic in Australia demonstrated that the bacterial group of the lake water was minimally different than that of both the groundwater and the sediment, and was dominated by a solitary OTU that was associated with Salinisphaera. In addition, pathways that had close relation with halotolerance were identified in the metagenomes, as were genes related with biological based synthesis of defensive carotenoids (Zaikova et al., 2018). The current study identified bacterial Niveispirillum as the most abundant genus group. Specifically, it was recorded in the highest abundance within the salt bearing sediment (SY) and the lowest within the clay sediment (NT). The Niveispirillum genus with members such as the Niveispirillum cyanobacteriorum sp. Nov has been associated with extreme environments where they enhance the restoration of the degraded sediment (Cai et al., 2015). Indeed, through heatmap analysis, it was confirmed that clay sediment types had the highest abundance of the dominating genera. Other similar studies have also recorded that aerobic anoxygenic phototrophic bacteria communities, including genus Niveispirillum are some of the overlooked drivers in promoting the production of biobased sediment crusts (Beazley et al., 2012; Tang et al., 2018).

\section{Microbial diversity}

It is turning out to be obvious that the bacterial phyla co-happening at a given site possess a similar natural specialty and the spatial variability can demonstrate the presence of various levels in the dissemination of some major ecological components, including the saltiness levels. Through this, it has been clear that the connection of certain groups of microbes to the level of saltiness is by all accounts an important condition for the expansion of the species having a place with those specific groupings (Canfora et al., 2014). The current study also indicated that Alpha diversity index from the ACE, 
CHAO1, Shannon and Simpson had higher values within the clay sediment type and the lowest values within the salt bearing sediment. This also demonstrated the influence of salt levels within the sediment on the occurrence and distribution of bacterial communities.

\section{Metabolic function analysis}

The Kyoto Encyclopedia of Genes and Genomes (KEGG) functional prediction analysis has been applied on studies of the metabolic function changes of community samples at different sediment types. Additionally, the Clusters of Orthologous Groups (COGs) has been used to complement KEGG to compare the protein sequences of complete genomes of different types of samples (Nho et al., 2018). The current study also employed KEGG and COG to provide an understanding on metabolomic functions and the protein sequence comparison. The study result pointed out membrane transport, amino acid metabolism, carbohydrate metabolism as the major molecular activities across the sediment types. Through COG and LEfSe analysis based on taxonomical composition of samples according to different grouping conditions for linear discrimination analysis (LDA), there was less variation in the metabolomic functions of groups between the sandstone sediment and the clay sediment types, but more variation between the salt bearing sediment to the other sediment types.

\section{Volatile organic carbon content}

Soils may serve as sources or sinks of VOCs. VOCs assume a basic part in the guideline of the variety, syntheses, and network designs of bacterial networks in saline conditions and are additionally significant natural elements since they supply supplements for microbial cells and intervene in intercellular collaborations (Ding et al., 2020). The current study finding on the VOCs across the different sediment indicated that values for ethanol, 1-Butanol M, 2-Octanol and n-Hexyl acetate were relatively the highest within the clay sediment, the values for Cyclohexanone, 5-Methyl-3-heptanone, formic acid, ethyl propionate, propyl butanoate $\mathrm{M}$, hexanal $\mathrm{M}$ and Benzaldehyde were relatively the highest within the sandstone sediment while values for Acetone, ethyl acetate M, Butyl butyrate M, Furfural M, Heptanal, Octanal, Nonanal M and Nonanal D were the highest within the salt bearing sediment. Within the clay sediment, Ethanol was the most abundant VOC, the most abundant VOC within the sandstone sediment was propyl butanoate $\mathrm{M}$, while Butyl butyrate $\mathrm{M}$ was the most abundant. Across all the sediments types, ethanol was the most abundant while n-Hexyl acetate was the least abundant VOC. Ambient concentrations of volatile alcohols such as ethanol and methanol had been determined in saline environments leading to hypothesis that they could be having a common source. The biogeochemistry of ethanol in sediments points to the possible functional achievement of ethanol in the worldwide carbon cycle (Roebuck et al., 2016).

\section{Conclusions and recommendations}

From the study findings, it can be concluded that;

- There exists a distinct variability in microbial communities' diversity and metabolic functions between the different sediment types of the East Taijinar Salt Lake. The OTUs overlapped more between the clay sediment (TN) and sand stone sediment 
(FS) types, and NT sediment type had the highest number of unique OTUs while salt bearing sediment (SY) had the least.

- Most abundant phylum group was the Proteobacteria, thereafter Firmicutes followed by Actinobacteria. Niveispirillum was shown to be the most abundant genus group and specifically, it was recorded in the highest abundance within the salt bearing sediment (SY) and the lowest within the clay sediment (NT).

- Through the four indices, ACE, CHAO1, Shannon and Simpson, the highest diversity values occurred within the clay sediment type and the lowest values within the salt bearing sediment.

- Membrane transport, amino acid metabolism, carbohydrate metabolism were the major molecular activities across the sediment types and ethanol was the most abundant while n-Hexyl acetate was the least abundant VOC across all the sediment types.

As a recommendation, there is a need for in-depth study on the relationship between the salt lake microbial communities and the economically potential VOCs for further insert in the management and use of the lake resources.

Data availability statement. The data obtained from this study is available on reasonable request forwarded through the corresponding author.

Acknowledgement. This work was supported by the Natural Science Foundation of Qinghai Province (Grant number: 2019-ZJ-911).

\section{REFERENCES}

[1] Barker, M. S., Dlugosch, K. M., Dinh, L., Challa, R. S., Kane, L. C., King, M. G., Rieseberg, L. H. (2010): EvoPipes.net: Bioinformatic Tools for Ecological and Evolutionary Genomics. - Evolutionary Bioinformatics 6: 143-149. https://doi.org/10.4137/EBO.S5861.

[2] Baxter, B. K. (2018): Great Salt Lake microbiology: a historical perspective. - Int Microbiol. 21(3): 79-95. https://doi.org/10.1007/s10123-018-0008-z.

[3] Beazley, M. J., Martinez, R. J., Rajan, S., Powell, J., Piceno, Y. M., Tom, L. M., Andersen, G. L., Hazen, T. C., Van Nostrand, J. D., Zhou, J., Mortazavi, B., Sobecky, P A. (2012): Microbial community analysis of a coastal salt marsh affected by the Deepwater Horizon oil spill. - PloS one 7(7): e41305. https://doi.org/10.1371/journal.pone.0041305.

[4] Boggsa, D. A., Boggs, G. S., Eliota, I., Knott, B. (2006): Regional patterns of Salt Lake morphology in the lower Yarra Yarra drainage system of Western Australia. - Journal of Arid Environments 64(1): 97-115. https://doi.org/10.1016/j.jaridenv.2005.04.010.

[5] Britannica. (2019): Great Salt Lake. - Encyclopedia Britannica, https://www.britannica.com/place/Great-Salt-Lake. Accessed 1 May 2021.

[6] Cai, H., Wang, Y., Xu, H., Yan, Z., Jia, B., Maszenan, A. M., Jiang, H. (2015): Niveispirillum cyanobacteriorum sp. nov., a nitrogen-fixing bacterium isolated from cyanobacterial aggregates in a eutrophic lake. - International Journal of Systematic and Evolutionary Microbiology 65(8): 2537-2541. https://doi.org/10.1099/ijs.0.000299.

[7] Canfora, L., Bacci, G., Pinzari, F., Lo Papa, G., Dazzi, C., Benedetti, A. (2014): Salinity and Bacterial Diversity: To What Extent Does the Concentration of Salt Affect the Bacterial Community in a Saline Soil? - PLoS One: 9(9): e106662. https://doi.org/10.1371/journal.pone.0106662.

[8] Chao, A., Chiu, C. (2016): Species Richness: Estimation and Comparison. - Wiley StatsRef: Statistics Reference Online, pp. 1-26. 
[9] Chindapana, N., Niamnuyb, C., Devahastin, S. (2018): Physical properties, morphology and saltiness of salt particles as affected by spray drying conditions and potassium chloride substitution. - Powder Technology 326: 265-271.

https://doi.org/10.1016/j.powtec.2017.12.014.

[10] Ding, X., Liu, K., Gong, G., Tian, L., Ma, J. (2020): Volatile organic compounds in the salt-lake sediments of the Tibet Plateau influence prokaryotic diversity and community assembly. - Extremophiles 24(2): 307-318. https://doi.org/10.1007/s00792-020-01155-3.

[11] Dong, H., Zhang, G., Jiang, H., Yu, B., Chapman, L. R., Lucas, C. R., Fields, M. W. (2006): Microbial diversity in sediments of saline Qinghai Lake, China: linking geochemical controls to microbial ecology. - Microb Ecol. 51(1): 65-82.

https://doi.org/10.1007/s00248-005-0228-6.

[12] Freire, P., Andrade, C., Viveiros, F., Silva, C., Coutinho, R., Cruz, J. (2014): Mineral water occurrence and geochemistry in the Azores volcanic archipelago (Portugal): insight from an extended database on water chemistry. - Environmental Earth Sciences 73: 2749-2762. https://doi.org/10.1007/s12665-014-3157-1.

[13] Grant, W. D., Sorokin, D. Y. (2011): Distribution and Diversity of Soda Lake Alkaliphiles. - In: Horikoshi, K. (ed.) Extremophiles Handbook. Springer, Tokyo, pp. 27-54. https://doi.org/10.1007/978-4-431-53898-1_3.

[14] Guan, T. W., Lin, Y. J., Ou, M. Y., Chen, K. B. (2020): Isolation and diversity of sediment bacteria in the hypersaline aiding lake, China. - PloS one 15(7): e0236006. https://doi.org/10.1371/journal.pone.0236006.

[15] Han, R., Zhang, X., Liu, J., Long, Q., Chen, L., Liu, D., Zhu, D. (2017): Microbial community structure and diversity within hypersaline Keke Salt Lake environments. - Can. J. Microbiol. 63(11): 895-908. https://doi.org/10.1139/cjm-2016-0773.

[16] Hollister, E. B., Engledow, A. S., Hammett, A. J., Provin, T. L., Wilkinson, H. H., Gentry, T. J. (2010): Shifts in microbial community structure along an ecological gradient of hypersaline soils and sediments. - ISME 4(6): 829-38. https://doi.org/10.1038/ismej.2010.3.

[17] Insam, H., Seewald, M. S. A. (2010): Volatile organic compounds (VOCs) in soils. - Biol Fertil Soils 46: 199-213. https://doi.org/10.1007/s00374-010-0442-3.

[18] Jones, B. E., Grant, W. D., Collins, N. C., Mwatha, W. E. (1994): Alkaliphiles: Diversity and Identification. - In: Priest, F. G., Ramos-Cormenzana, A., Tindall, B. J. (eds.) Bacterial Diversity and Systematics. Federation of European Microbiological Societies Symposium Series, 75: Springer, Boston, MA. https://doi.org/10.1007/978-1-4615-1869-3_12.

[19] Jones, B. E., Grant, W. D., Duckworth, A. W., Owenson, G. G. (1998): Microbial diversity of soda lakes. - Extremophiles 2(3): 191-200. https://doi.org/10.1007/s007920050060.

[20] Kambura, A. K., Mwirichia, R. K., Kasili, R. W., Karanja, E. N., Makonde, H. M., Boga, H. I. (2016): Bacteria and Archaea diversity within the hot springs of Lake Magadi and Little Magadi in Kenya. - BMC Microbiology 16(1): 136. https://doi.org/10.1186/s12866016-0748-x.

[21] Kasper, U. K., Alexander, L., Trine, F. J., Trine, R. T., Michael, W., Kjeld, I. (2007): Diversity of sulfate-reducing bacteria from an extreme hypersaline sediment, Great Salt Lake (Utah). - FEMS Microbiology Ecology 60(2): 287-298. https://doi.org/10.1111/j.1574-6941.2007.00288.x.

[22] Last, W. M. (2002): Geolimnology of salt lakes. - Geosci. J. 6: 347-369. https://doi.org/10.1007/BF03020619.

[23] Lin, Q., Xu, L., Hou, L., Liu, Z., Jeppesen, E., Han, B. (2017): Responses of trophic structure and zooplankton community to salinity and temperature in Tibetan lakes: Implication for the effect of climate warming. - Water Research 124: 618-629. https://doi.org/10.1016/j.watres.2017.07.078.

[24] Mellouki, A., Wallington, T., Chen, J. (2015): Atmospheric Chemistry of Oxygenated Volatile Organic Com pounds (OVOCs): Impacts on Air Quality and Climate. - Chemical 
Reviews, American Chemical Society 115(10): 3984-4014. https://doi.org/10.1021/cr500549nff.

[25] Mesbah, N. M., Abou-El-Ela, S. H., Wiegel, J. (2007): Novel and unexpected prokaryotic diversity in water and sediments of the alkaline, hypersaline lakes of the Wadi an Natrun, Egypt. - Microb. Ecol. 54(4): 598-617. https://doi.org/10.1007/s00248-006-9193-y.

[26] Mianping, Z., Jiayou, T., Junying, L., Fasheng, Z. (1993): Chinese saline lakes. - In: Hurlbert, S. H. (ed.) Saline Lakes V. Developments in Hydrobiology 87. Springer, Dordrecht. https://doi.org/10.1007/978-94-011-2076-0_3.

[27] Nho, S. W., Abdelhamed, H., Paul, D., Park, S., Mauel, M. J., Karsi, A., Lawrence, M. L. (2018): Taxonomic and Functional Metagenomic Profile of Sediment from a Commercial Catfish Pond in Mississippi. - Front. Microbiol. 9: 2855. https://doi.org/10.3389/fmicb.2018.02855.

[28] Oren, A., Fischel, U., Aizenshtat, Z., Krein, E. B., Reed, R. H. (1994): Osmotic adaptation of microbial communities in hypersaline microbial mats. - In: Stal, L. J., Caumette, P. (eds.) Microbial Mats. NATO ASI Series (Series G: Ecological Sciences), Vol 35. Springer, Berlin, Heidelberg. https://doi.org/10.1007/978-3-642-78991-5_14.

[29] Rasuk, M. C., Fernández, A. B., Kurth, D., Contreras, M., Novoa, F., Poiré, D., Farías, M. E. (2016): Bacterial Diversity in Microbial Mats and Sediments from the Atacama Desert. - Microb Ecol. 71(1): 44-56. doi: https://doi.org/10.1007/s00248-015-0649-9.

[30] Roebuck, J. A., Avery, G. B., Felix, J. D., Kieber, R. J., Mead, R. N., Skrabal, S. A. (2016). Biogeochemistry of Ethanol and Acetaldehyde in Freshwater Sediments. - Aquat Geochem. 22: 177-195. https://doi.org/10.1007/s10498-015-9284-9.

[31] Ruginescu, R., Gomoiu, I., Popescu, O., Cojoc, R., Neagu, S., Lucaci, I., BatrinescuMoteau, C., Enache, M. (2020): Bioprospecting for Novel Halophilic and Halotolerant Sources of Hydrolytic Enzymes in Brackish, Saline and Hypersaline Lakes of Romania. Microorganisms 8(12): 1903. https://doi.org/10.3390/microorganisms8121903.

[32] Tang, K., Jia, L., Yuan, B., Yang, S., Li, H., Meng, J., Zeng, Y., Feng, F. (2018): Aerobic Anoxygenic Phototrophic Bacteria Promote the Development of Biological Soil Crusts. Frontiers in microbiology 9: 2715. https://doi.org/10.3389/fmicb.2018.02715.

[33] Tazi, L., Breakwell, D. P., Harker, A. R., Crandall, K. A. (2014): Life in extreme environments: microbial diversity in Great Salt Lake, Utah. - Extremophiles 8(3): 525-35. https://doi.org/10.1007/s00792-014-0637-x.

[34] Thukral, A. K. (2017): A review on measurement of Alpha diversity in biology. Agricultural Research Journal 54(1): 1-10.

[35] Ventosa, A., de la Haba, R. R., Sánchez-Porro, C., Papke, R. T. (2015): Microbial diversity of hypersaline environments: a metagenomic approach. - Curr Opin Microbiol. 25: 80-87. https://doi.org/10.1016/j.mib.2015.05.002.

[36] Vogt, J. C., Abed, R. M. M., Albach, D. C., Palinska, K. A. (2017): Bacterial and Archaeal Diversity in Hypersaline Cyanobacterial Mats Along a Transect in the Intertidal Flats of the Sultanate of Oman. - Microb Ecol. 75(2): 331-347. https://doi.org/10.1007/s00248017-1040-9.

[37] Williams, W. D. (1991): Chinese and Mongolian saline lakes: a limnological overview. Hydrobiologia 210: 39-66. https://doi.org/10.1007/BF00014322.

[38] Wu, C., Wang, C., Wang, S., Wang, W., Yuan, B., Qi, J., Wang, B., Wang, H., Wang, C., Song, W., Wang, X., Hu, W., Lou, S., Ye, C., Peng, Y., Wang, Z., Huangfu, Y., Xie, Y., Zhu, M., Zheng, J., Wang, X., Jiang, B., Zhang, Z., Shao, M. (2020): Measurement report: Important contributions of oxygenated compounds to emissions and chemistry of volatile organic compounds in urban air. - Atmos. Chem. Phys. 20: 14769-14785. https://doi.org/10.5194/acp-20-14769-2020.

[39] Yu, D., Kuenen, J. G. (2005): Chemolithotrophic haloalkaliphiles from soda lakes. - FEMS Microbiology Ecology 52(3): 287-295. https://doi.org/10.1016/j.femsec.2005.02.012. 
[40] Zaikova, E., Benison, K. C., Mormile, M. R., Johnson, S. S. (2018): Microbial communities and their predicted metabolic functions in a desiccating acid Salt Lake. - Extremophiles 22(3): 367-379. https://doi.org/10.1007/s00792-018-1000-4.

[41] Zheng, M. (2011): Resources and eco-environmental protection of salt lakes in China. Environ Earth Sci. 64: 1537-1546. https://doi.org/10.1007/s12665-010-0601-8. 